Notfall Rettungsmed 2015 · 18:653-654

DOI 10.1007/s10049-015-0102-0

Published online: 5 November 2015

(c) Springer-Verlag Berlin Heidelberg 2015

\author{
J. Nolan ${ }^{1,2}$ \\ ${ }^{1}$ University of Bristol, Bristol, UK \\ ${ }^{2}$ Anaesthesia and Intensive Care Medicine, Royal United Hospital, Bath, UK
}

\title{
2015 Resuscitation Guidelines
}

This issue of Notfall+Rettungsmedizin includes the German translation of the 2015 European Resuscitation Council (ERC) Guidelines. This translation of the ERC guidelines is the result of collaboration between the German Resuscitation Council (GRC), the Austrian Resuscitation Council (ARC) and the Swiss Resuscitation Council (SRC) and as such is an important landmark for advancing clinical resuscitation in the German-speaking world. Similar collaborations are taking place throughout the world as the international resuscitation community is implementing the recommendations that have been made by the International Liaison Committee on Resuscitation (ILCOR).

Since 2000, ILCOR has published its International Consensus on Cardiopulmonary Resuscitation (CPR) and Emergency Cardiovascular Care (ECC) Science with Treatment Recommendations (CoSTR) in 5-year cycles. The conclusions and recommendations of the $2010 \mathrm{CoSTR}$ were published at the end of 2010 [1]. The most recent ILCOR 2015 International Consensus Conference on CPR Science was held in Dallas in February 2015; the consensus science statements and treatment recommendations were published simultaneously in Resuscitation and Circulation $[2,3]$.

Current member organisations of ILCOR comprise the American Heart Association (AHA), the European Resuscitation Council (ERC), the Heart and Stroke Foundation of Canada, the Australian and New Zealand Committee on Resuscitation, the Resuscitation Council of Southern Africa, the InterAmerican Heart Foundation, and the Resuscitation Council of Asia. For the 2015 evidence evaluation process ILCOR formed seven task forces: basic life support (BLS), advanced life support (ALS), acute coronary syndromes (ACS), paediatric BLS and ALS, neonatal resuscitation, education implementation and teams (EIT), and, for the first time, first aid. Using the PICO [population, intervention, comparator, outcome] format, each task force identified and prioritised the questions to be addressed and then performed detailed systematic reviews. The task forces used the methodological approach for evidence evaluation and development of recommendations proposed by the Grading of Recommendations, Assessment, Development, and Evaluation (GRADE) Working Group [4]. A detailed search for relevant articles was performed in each of three online databases (MEDLINE, Embase, and the Cochrane Library) [5]. The quality of the evidence (or confidence in the estimate of the effect) was categorised as high, moderate, low or very low [6], based on the study methodologies and the risk of bias, inconsistency, indirectness, imprecision and publication bias. Written summaries of evidence for each outcome (the Consensus on Science statements) were drafted by the evidence reviewers and then discussed, debated and refined by the task forces until consensus was reached. Whenever possible, consensus-based treatment recommendations were created. These recommendations (designated as strong or weak and either for or against a therapy or diagnostic test) were accompanied by an overall assessment of the evidence, and a statement from the task force about the values and preferences that underpinned the recommendations.

During the 3 years leading up to the ILCOR 2015 Consensus Conference, 250 evidence reviewers from 39 countries completed 169 systematic reviews addressing resuscitation or first aid questions. A web-based information system was built to support the creation of scientific statements and recommendations. An online platform, the Scientific Evaluation and
Evidence Review System (SEERS), was developed to support the task force activities. Draft consensus on science statement and treatment recommendations were published online on SEERS for public review and comment. The 2015 Consensus Conference was attended by 232 participants from 39 countries; $64 \%$ of the attendees came from outside the United States.

As in 2010, a robust conflict of interest (COI) management policy was enforced throughout the process [5]. A dual-screen projection was used for all sessions of the ILCOR 2015 Consensus Conference. In all, one screen displayed the presenter's COI disclosures continuously throughout their presentation and this screen was also used to display the relevant COIs whenever participants spoke.

The 2015 CoSTR forms the basis for the 2015 ERC resuscitation guidelines but the two outputs are distinct $[2,7]$. The treatment recommendations in CoSTR are based purely on the available science and are generally broad in scope-they often do not inform the resuscitation practitioner precisely how to treat the patient. The ERC Guidelines are much more practical and tend to be more didactic, that is they tell the clinician exactly what to do. The AHA has also published an update of the 2010 guidelines based on the 2015 CoSTR and, in the same way, they reflect the practical implementation of resuscitation in the United States. Guidelines incorporate economic, cultural and geographical factors and it is inevitable that there are subtle differences between the ERC and AHA guidelines. This is best reflected in the algorithms, which although based on the same science, are different. Unfortunately, when it comes to the practical implementation of resuscitation we lack robust science, thus interventions, such as the precise timing of drug deliv- 
ery, often end up reflecting existing regional practice and are not standardised internationally.

In comparison with the 2010 ERC guidelines, most changes in the 2015 ERC guidelines are relatively subtle. This is likely to be welcomed by most clinicians, and indeed laypeople, who often struggle to remember the 'latest' guidelines. Stability in the guidelines will enhance teamwork because we will not have to go through the 1-3 year transition period, experienced by many of us in the past, during which clinicians are all trying to do things differently. Having said that, there are some important changes in the 2015 guidelines. In BLS, there is emphasis on the rescuer calling the emergency medical services for the victim who is unresponsive and not breathing normallythe 'open airway' instruction has now disappeared from the BLS algorithm [8]. In ALS, the use of waveform capnography is emphasised and the use of extracorporeal life-support techniques are acknowledged [9]. The post-resuscitation care guidelines are now in a separate section and have been written in collaboration with the European Society of Intensive Care Medicine [10]. There are changes in the recommendations for targeted temperature management and new guidelines on prognostication [11].

There is a good evidence that survival from cardiac arrest is improving and we hope that these 2015 ERC guidelines will contribute to further improvements in outcome for victims of cardiac arrest throughout the Europe [12-14].

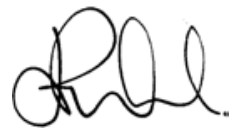

J. Nolan

\section{Corresponding address}

\section{J. Nolan}

University of Bristol, Bristol

jerry.nolan@nhs.net

\section{References}

1. Nolan JP, Hazinski MF, Billi JE et al (2010) Part 1: executive summary: 2010 International Consensus on cardiopulmonary Resuscitation and emergency cardiovascular care science with treatment recommendations. Resuscitation 81(Suppl 1):e1-e25

2. Nolan JP, Hazinski MF, Aicken R et al (2015) Part I. Executive summary: 2015 International Consensus on cardiopulmonary Resudcitation and emergency cardiovascular care science with treatment recommendations. Resuscitation 95:e1-e32

3. Hazinski MF, Nolan JP, Aicken R et al (2015) Part I. Executive summary: 2015 International Consensus on cardiopulmonary resudcitation and emergency cardiovascular care science with treatment recommendations. Circulation 132(16 Suppl 1):2-39

4. Overview of the GRADE Approach. In: GRADE Handbook. http://www.guidelinedevelopment. org/handbook/-h.svwngs6pm0f2. Accessed 27 Sept 2015

5. Morley PT, Lang E, Aickin R et al (2015) Part 2: evidence evaluation and management of conflict of interest for the ILCOR 2015 consensus on science and treatment recommendations. Resuscitation 95:e33-e41

6. Schunemann HJ, Oxman AD, Brozek J et al (2008) Grading quality of evidence and strength of recommendations for diagnostic tests and strategies. BMJ 336:1106-1110

7. Monsieurs K, Nolan JP, Bossaert LL et al (2015) European Resuscitation Council Guidelines for Resuscitation 2015 Section 1 executive summary. Resuscitation $95: 1-80$

8. Perkins GD, Handley AJ, Koster KW et al (2015) European Resuscitation Council Guidelines for Resuscitation 2015 Section 2 adult basic life support and automated external defibrillation. Resuscitation 95:81-98

9. Soar J, Nolan JP, Bottiger BW et al (2015) European Resuscitation Council Guidelines for Resuscitation 2015 Section 3 adult advanced life support. Resuscitation 95:99-146

10. Nolan JP, Soar J, Cariou A et al (2015) European Resuscitation Council and European Society of Intensive Care Medicine Guidelines for Resuscitation 2015 Section 5 Post Resuscitation Care. Resuscitation 95:201-221

11. Sandroni C, Cariou A, Cavallaro F et al (2014) Prognostication in comatose survivors of cardiac arrest: an advisory statement from the European Resuscitation Council and the European Society of Intensive Care Medicine. Resuscitation 85:1779-1789

12. Girotra S, Nallamothu BK, Spertus JA et al (2012) Trends in survival after in-hospital cardiac arrest. N Engl J Med 367:1912-1920

13. Chan PS, McNally B, Tang F, Kellermann A, Group CS (2014) Recent trends in survival from out-ofhospital cardiac arrest in the United States. Circulation 130:1876-1882

14. Wissenberg M, Lippert FK, Folke F et al (2013) Association of national initiatives to improve cardiac arrest management with rates of bystander intervention and patient survival after out-of-hospital cardiac arrest. JAMA 310:1377-1384

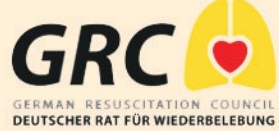

\section{Der GRC informiert}

Der GRC hat alle Informationen zu

der deutschen Übersetzung der ERC-Leitlinien auf der Homepage zusammengestellt. Der GRC bedankt sich für die Unterstützung bei seinen Businesspartnern.

www.grc-org.de

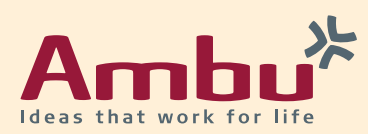

SScorpuls ${ }^{\circ}$

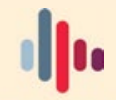

HANS PETER ESSER
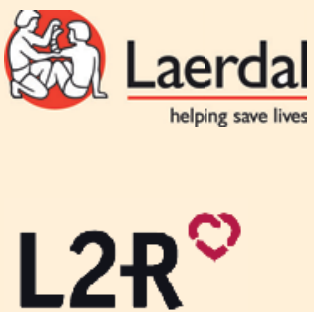

LEARN TO RESCUE

PHILIPS

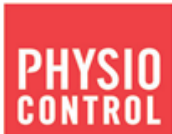

PRIMEDIC

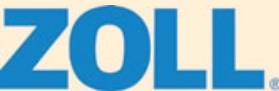

